\title{
Velocidade de estabelecimento em cultivares de arroz irrigado como característica para aumentar a habilidade competitiva com plantas concorrentes
}

\author{
Speed of establishment in flooded rice cultivars as a trait to increase the competitive \\ ability with competitor plants
}

\author{
Nilson Gilberto Fleck ${ }^{1}$ Alvadi Antonio Balbinot Junior ${ }^{2}$ \\ Dirceu Agostinetto ${ }^{3}$ Mauro Antônio Rizzardi ${ }^{3}$
}

RESUMO

Plantas que apresentam rápido estabelecimento possuem prioridade na utilização dos recursos do meio; por isso, levam vantagem na competição com plantas vizinhas. $O$ objetivo deste trabalho foi detectar variações na velocidade de estabelecimento de cultivares de arroz irrigado. Para isso, conduziram-se três experimentos: dois deles em casa-devegetação e outro em campo. Em ambas as condições, investigou-se o comportamento de nove cultivares de arroz. Para caracterizar a rapidez de estabelecimento, avaliaramse: velocidade de emergência das plântulas, estatura de planta, área folhar e massa da parte aérea aos 15 dias após a semeadura. Os genótipos Ligeirinho e XL 6 mostraram características que lhes conferem rápido estabelecimento, enquanto, Bluebelle e Formosa apresentaram características indicativas de lento estabelecimento.

Palavras-chave: interferência, velocidade de emergência, crescimento inicial, ocupação de nicho.

\section{ABSTRACT}

Plants that present fast establishment possess priority in utilizing environmental resources; therefore, they present advantage in competitive ability with their neighbours. The objective of this research was to detect variations in speed of establishment in flooded rice cultivars. This way, there were conducted three experiments, two of them in the greenhouse and the other in the field. In both conditions, it was investigated the behavior of nine cultivars. In order to characterize speed of establishment, there were evaluated: emergency velocity, plant height, leaf area, and aerial weight of the seedlings 15 days after sowing. The genotypes Ligeirinho and XL 6 showed characteristics that attribute them fast establishment; whereas, Bluebelle and Formosa presented characteristics indicative of slow seedling establishment.

Key words: interference, emergency velocity, early growth, niche occupation.

\section{INTRODUÇÃO}

A utilização de cultivares com elevada capacidade competitiva é importante para o manejo cultural de plantas daninhas. Na busca por recursos limitados no meio, há prêmio aparente para aqueles vegetais que exibem estabelecimento precoce. A planta em crescimento deve apoderar-se rapidamente do espaço, representado pelos recursos, sendo seu sucesso competitivo dependente do uso antecipado desses. Cada planta pára de crescer quando seu espaço é restringido pelas concorrentes, de tal forma que os últimos indivíduos a aparecer crescem muito pouco. Assim, os vegetais mais competitivos geralmente são os primeiros a emergir, indicando que a época de emergência torna-se mais importante do que o arranjo

\footnotetext{
${ }^{1}$ Engenheiro Agrônomo, PhD, Professor do Departamento de Plantas de Lavoura da Faculdade de Agronomia da Universidade Federal do Rio Grande do Sul, (UFRGS). Bolsista do CNPq, CP 776, 91501-970, Porto Alegre, RS. E-mail: fleck@vortex.ufrgs.br. Autor para correspondência.

${ }^{2}$ Engenheiro Agrônomo, Aluno do Programa de Pós-graduação em Fitotecnia, UFRGS.

${ }^{3}$ Engenheiro Agrônomo, Mestre, Aluno do Programa de Pós-graduação em Fitotecnia da UFRGS.
} 
espacial de indivíduos na determinação do potencial competitivo dessa população de plantas (FISCHER \& MILES, 1973).

Plantas que possuem emergência rápida $\mathrm{e}$ uniforme, conseguem competir mais eficientemente pelos recursos do meio (DIARRA et al., 1985; SHURTLEFF \& COBLE, 1985; ROMAN et al., 1999; NI et al., 2000). Em sorgo, a velocidade de emergência se correlacionou positivamente com a capacidade das linhagens em competir com plantas daninhas (GUNEYLI et al., 1969). Neste sentido, FISCHER \& MILES (1973), pesquisando os processos de interferência entre vegetais, formularam o princípio teórico em que, quanto maior for a velocidade de estabelecimento de uma planta, maior é o volume aéreo e edáfico ocupado e explorado pela mesma.

Existem três fatores-chave na predição das relações de interferência entre plantas daninhas e culturas: época de emergência, arranjo espacial e velocidade de crescimento das plantas (RADOSEVICH et al., 1997). As primeiras plântulas a emergir, provavelmente, apresentarão maior produtividade, porque elas adquirem prioridade na utilização de água, luz e nutrientes; ou seja, ocupam precocemente o nicho (FIRBANK \& WATKINSON, 1985). Nicho é o termo usado para descrever a posição ocupada por uma espécie dentro da comunidade (RADOSEVICH et al., 1997).

Plantas que utilizam os recursos do meio mais precocemente conseguem sombrear as demais, reduzindo a quantidade e a qualidade da luz incidente sobre os vizinhos (KNEZEVIC \& HORAK, 1998). Por exemplo, a emergência rápida do arroz-vermelho (Oryza spp.) é fator importante para o estabelecimento de suas plântulas; assim, esta infestante ocupa logo os espaços e compete mais precocemente pelos recursos do ambiente em relação às cultivares de arroz e, por isso, leva vantagem na competição (DIARRA et al., 1985).

Plantas daninhas que conseguem se estabelecer antes da cultura formam plantas com elevado tamanho e alta produção de sementes, aumentando o potencial de reinfestação da área com sementes que estarão aptas a emergir nos cultivos subseqüentes (CHICOYE et al., 1995). Outro problema decorrente do estabelecimento tardio das culturas, em relação às plantas daninhas, é a necessidade de incremento da dose herbicida para o controle satisfatório das plantas daninhas (DIELEMAN et al., 1996).

Diante deste contexto, evidencia-se a importância do rápido estabelecimento da cultura na redução de danos ocasionados pelas plantas daninhas. Práticas de manejo da cultura, como utilização de sementes de qualidade, adequado manejo do solo e semeadura realizada na época e na profundidade recomendadas, aumentam sensivelmente as chances de colocar o cultivo em posição competitiva vantajosa. A adoção destas práticas, juntamente com a utilização de cultivares que mostrem rapidez de estabelecimento, constituem pontos chaves para acelerar o crescimento da cultura e privilegiar seu sucesso na competição com plantas daninhas.

Deste modo, o objetivo deste trabalho foi investigar variações na velocidade de estabelecimento de cultivares de arroz irrigado, compreendendo as fases de emergência e de crescimento inicial das plântulas.

\section{MATERIAL E MÉTODOS}

Foram realizados três experimentos, sendo dois em casa-de-vegetação e outro em campo. Os estudos realizados no primeiro caso foram conduzidos no Departamento de Plantas de Lavoura da Faculdade de Agronomia da Universidade Federal do Rio Grande do Sul (UFRGS), município de Porto Alegre, RS. Eles foram instalados em vasos com capacidade volumétrica de um litro e diâmetro de $15 \mathrm{~cm}$, utilizandose como substrato, solo oriundo de lavoura orizícola, classificado como Planossolo Hidromórfico Eutrófico arênico, pertencente à unidade de mapeamento Vacacaí (EMBRAPA, 1999).

Os experimentos em casa-de-vegetação foram conduzidos nos meses de janeiro e outubro de 2001. As cultivares de arroz utilizadas foram: Bluebelle, BRS Ligeirinho, EEA 406, El Paso L 144, IAS 12-9 Formosa, IR 841, IRGA 418, IRGA 421 e XL 6. O número de sementes colocadas por vaso foi ajustado para cada cultivar de acordo com seu poder germinativo, determinado através de teste de germinação em laboratório, objetivando-se o estabelecimento de 20 plantas por vaso. A profundidade de semeadura foi uniformizada em $1,5 \mathrm{~cm}$. Os vasos, com fundo perfurado, foram mantidos dentro de bandejas plásticas, através das quais foi fornecido água para manter o solo úmido através de capilaridade. $\mathrm{O}$ delineamento experimental utilizado foi completamente casualizado, com seis repetições por cultivar.

A velocidade de emergência foi avaliada com base no critério agronômico, o qual consistiu na contagem diária das plântulas emergidas por vaso até o décimo dia após a semeadura (DAS). Considerou-se plântula emergida aquela que apresentava coleóptilo com comprimento superior a $1,5 \mathrm{~cm}$. Para o cálculo do índice de velocidade de emergência (IVE) foi utilizada a equação sugerida por POPINIGIS (1977): IVE $=\mathrm{N}_{1} / \mathrm{D}_{1}$

Ciência Rural, v. 33, n. 4, jul-ago, 2003. 
$+\mathrm{N}_{2} / \mathrm{D}_{2}+\mathrm{N}_{\mathrm{n}} / \mathrm{D}_{\mathrm{n}}$; onde: IVE $=$ índice de velocidade de emergếncia; $\mathrm{N}_{1}^{\mathrm{n}}=$ número de plântulas emergidas no primeiro dia; $\mathrm{N}_{\mathrm{n}}=$ número acumulado de plântulas emergidas; $\mathrm{D}_{1}=$ primeiro dia de contagem; $\mathrm{D}_{\mathrm{n}}=$ número de dias contados após a semeadura.

No décimo DAS, foi realizado desbaste do excesso de plântulas nos vasos, mantendo-se as 10 mais vigorosas. No $14^{\circ} \mathrm{DAS}$, foram realizadas as seguintes determinações, utilizando-se três repetições por cultivar: área folhar - foi determinada em laboratório com auxílio de determinador de área folhar (modelo Area Meter 3100); estatura das plântulas de arroz - foi determinada através da mensuração da altura da sua parte aérea, tomando-se o comprimento desde o nível do solo até o ápice das mesmas, com o limbo folhar distendido; massa seca da parte aérea - foi determinada através da pesagem das plantas secas em estufa, até atingir massa constante, à temperatura de $65^{\circ} \mathrm{C}$.

O experimento em campo foi implantado no dia 18 de novembro de 2000, na Estação Experimental do Arroz (EEA), pertencente ao Instituto RioGrandense do Arroz (IRGA), em Cachoeirinha, RS. O solo da EEA é classificado como Planossolo Hidromórfico Eutrófico arênico, pertencente à unidade de mapeamento Vacacaí (EMBRAPA, 1999). O preparo do solo foi realizado através do método convencional, compreendendo uma lavração e duas gradagens. Cada unidade experimental apresentou área total de $4 \mathrm{~m}^{2}$ (2x2m) e área útil de $2,56 \mathrm{~m}^{2}(1,6 \times 1,6 \mathrm{~m})$.

Os tratamentos foram dispostos segundo o delineamento experimental completamente casualizado, com quatro repetições. Foram comparadas as mesmas cultivares avaliadas nos bioensaios de casa-de-vegetação. A densidade de semeadura foi ajustada para cada cultivar de acordo com seu poder germinativo, determinado em laboratório, objetivando-se uma densidade de 300 plantas. $\mathrm{m}^{-2}$. O teor de água no solo no momento da semeadura era próximo à capacidade de campo.

A velocidade de emergência das cultivares foi avaliada através da contagem das plântulas emergidas (com coleóptilo acima de $1,5 \mathrm{~cm}$ ) aos 6,8 , $10,12,14$ e 16 DAS. A unidade amostrada foi $0,5 \mathrm{~m}$ de fileira por parcela, sempre no mesmo local. Aos 16 DAS, considerou-se completada a fase de emergência. Através desses dados, calculou-se o índice de velocidade de emergência (IVE) para cada genótipo, através da equação proposta por POPINIGIS (1977).

Adicionalmente, aos 15 DAS foram amostradas cinco plântulas por parcela, nas quais foram realizadas as seguintes determinações: área folhar determinada em laboratório com auxílio de determinador de área folhar (modelo Area Meter 3100); estatura das plântulas de arroz - foi determinada através da mensuração da altura da sua parte aérea, tomandose o comprimento desde o nível do solo até o ápice das mesmas, com o limbo folhar distendido; massa seca da parte aérea - as partes aéreas das plântulas foram colocadas em estufa a $65^{\circ} \mathrm{C}$ até atingir massa constante, quando foram pesadas.

Os dados coletados nos experimentos conduzidos em casa-de-vegetação e no campo foram submetidos à análise de variância, através do teste $\mathrm{F}$ e as médias dos tratamentos foram comparadas aplicando-se o teste de Duncan, a 5\% de probabilidade de erro. Efetuou-se também análise de regressão polinomial para a variável velocidade de emergência em campo. Utilizaram-se os modelos de regressão linear, quadrático e exponencial para comparar o ajuste dos dados, selecionando-se o modelo que apresentava significância a 5\% de probabilidade de erro. Realizouse, também, análise de correlação linear simples entre as variáveis investigadas. A análise estatística foi realizada através do programa computacional SANEST.

\section{RESULTADOS E DISCUSSÃO}

Houve variação na velocidade de emergência entre as cultivares de arroz avaliadas em condição de campo (Figura 1). Os genótipos XL 6 (ciclo precoce) e Ligeirinho (super-precoce) apresentaram rápida emergência de plântulas, atingindo cerca de $90 \%$ de emergência aos 12 DAS. As cultivares El Paso, IR 841, IRGA 418, IRGA 421 e Formosa, por outro lado, apresentaram incremento linear na emergência no decorrer do período considerado. Através do teste ' $t$ ', compararam-se os coeficientes angulares e as intersecções para essas cultivares, os quais não diferiram significativamente entre si; por isso, a velocidade de emergência dessas cultivares pode ser expressa como uma única reta. Até 10 DAS, Bluebelle mostrou lenta emergência, cerca de $23 \%$; após, tendeu a acelerar o processo, alcançando $90 \%$ de emergência aos 14 DAS (Figura 1). As maiores diferenças entre os genótipos, para essa característica, tenderam a ocorrer ao redor do décimo DAS.

Quanto à análise de índice de velocidade de emergência (IVE), verificou-se que El Paso e Ligeirinho mostraram rápida emergência, tanto em casade-vegetação como no campo (Tabela 1). Por sua vez, a cultivar híbrida XL 6 obteve elevado IVE em campo e em um dos bioensaios. Em geral, as cultivares Formosa e Bluebelle mostraram lenta emergência em casa-devegetação; em campo, além dessas duas cultivares, IRGA 421 também mostrou reduzida velocidade de 


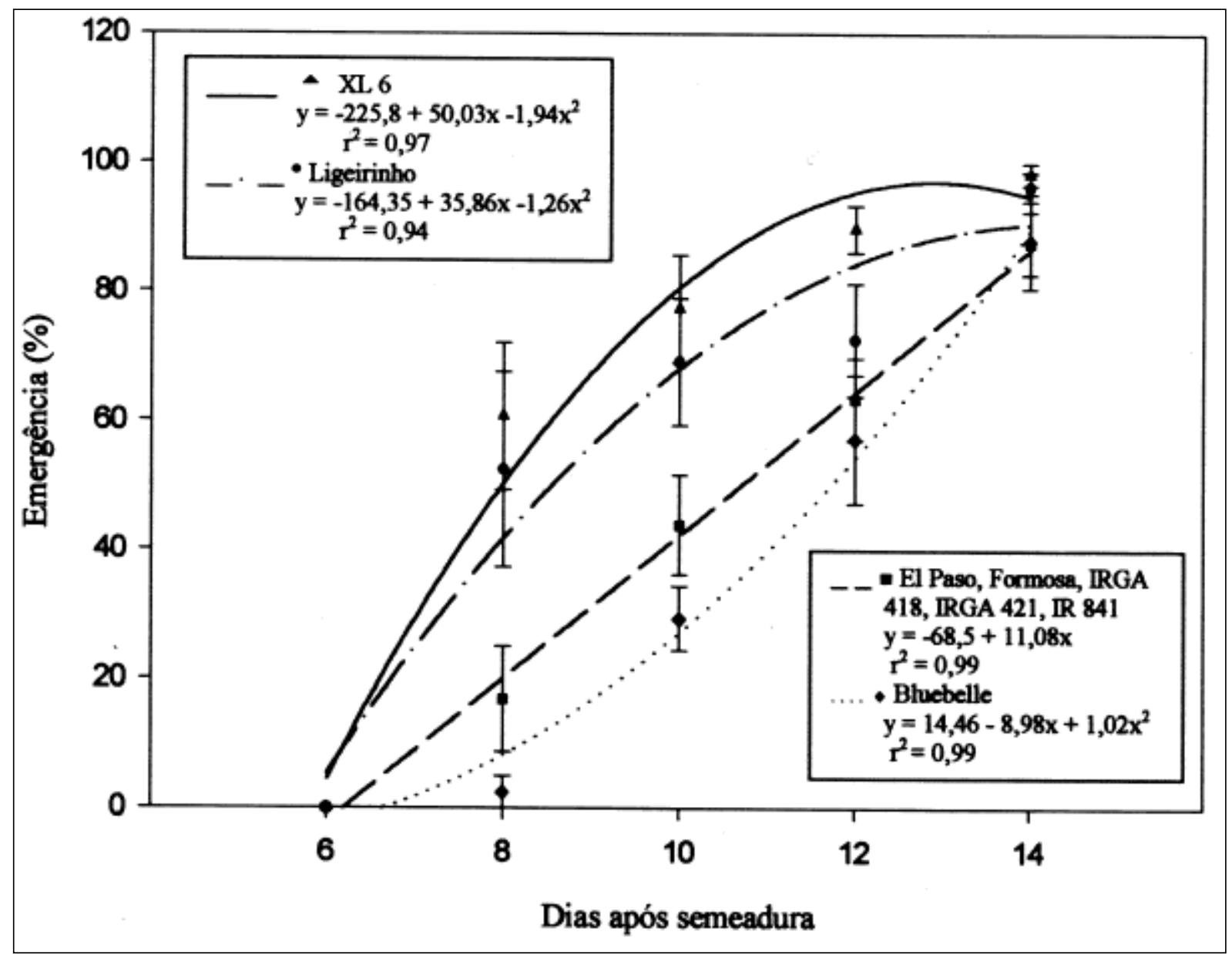

Figura 1- Evolução da emergência de plântulas de cultivares de arros do campo, EEA/IRGA, Cachoeirinha-RS, 2000.

emergência das plântulas. As cultivares IRGA 418 e IR 841, tanto em campo como em casa-de-vegetação, tenderam à posição próxima ou abaixo da média geral das cultivares. Também EEA 406 posicionou-se próximo à média. É razoável supor que as cultivares que demonstram lenta emergência apresentarão menor habilidade em competir com infestantes desde o início do ciclo. A rapidez de emergência correlaciona-se positivamente com o espaço ocupado e explorado pelos vegetais; por sua vez, este determina a quantidade de recursos disponíveis para o crescimento e desenvolvimento das plantas (FISCHER \& MILES, 1973). Uma comprovação dessa teoria foi relatada por O'DONOVAN et al. (2000), em que cultivares de cevada com maior velocidade de emergência conseguiram competir vantajosamente com Avena fatua.

Observa-se (Tabela 1) que os IVE de todas as cultivares avaliadas foram superiores no Bioensaio 1, conduzido em janeiro, comparativamente ao Bioensaio 2, realizado em outubro. É provável que essa diferença deva-se, principalmente, às menores temperaturas que costumam ocorrer no mês de outubro, em relação a janeiro. Sabe-se que a temperatura influencia significativamente na velocidade de emergência das sementes (Kigel \& Galili, 1995).

Além da velocidade de emergência, analisaram-se também variáveis de crescimento até 14 DAS em casa-de-vegetação, e até 15 DAS no campo (Tabela 2). Em casa-de-vegetação, Ligeirinho, IRGA 418 e EEA 406 destacaram-se por apresentar maior estatura de planta aos 14 DAS; enquanto no campo, XL 6, em acréscimo àquelas, também mostrou maior crescimento em altura. Contrariamente, Formosa, Bluebelle e IR 841 geralmente apresentaram as menores estaturas, quando se analisam os resultados de campo e casa-de-vegetação. O genótipo IRGA 421 posicionou-se próximo à média em ambas as condições. Não houve correlação entre velocidade de emergência e estatura de planta para o período 
Tabela 1 - Índices de velocidade de emergência de plântulas de cultivares de arroz, UFRGS, Porto Alegre-RS, 2000/01

\begin{tabular}{lccc}
\hline \multirow{2}{*}{ Cultivares de arroz } & \multicolumn{2}{c}{ Casa-de-vegetação } & Campo \\
\cline { 2 - 4 } & Bioensaio 1 (janeiro) & Bioensaio 2 (outubro) & (novembro) \\
\hline IRGA 421 & $14,9^{1} \mathrm{~b}^{2}$ & $11,5 \mathrm{~b}$ & $2,5 \mathrm{de}$ \\
BRS Ligeirinho & $16,7 \mathrm{a}$ & $13,6 \mathrm{a}$ & $5,68 \mathrm{ab}$ \\
IRGA 418 & $15,0 \mathrm{~b}$ & $11,1 \mathrm{bc}$ & $3,89 \mathrm{~cd}$ \\
XL 6 & $13,4 \mathrm{bc}$ & $13,1 \mathrm{a}$ & $6,50 \mathrm{a}$ \\
E1 Paso L 144 & $16,9 \mathrm{a}$ & $13,1 \mathrm{a}$ & $5,28 \mathrm{abc}$ \\
Bluebelle & $13,9 \mathrm{bc}$ & $11,2 \mathrm{bc}$ & $2,32 \mathrm{de}$ \\
IAS Formosa & - & $9,4 \mathrm{~d}$ & $2,06 \mathrm{e}$ \\
IR 841 & $14,4 \mathrm{~b}$ & $10,5 \mathrm{~cd}$ & $4,47 \mathrm{bc}$ \\
EEA 406 & $13,1 \mathrm{c}$ & $11,8 \mathrm{~b}$ & - \\
Médias & 14,0 & 11,7 & 4,10 \\
CV (\%) & 8,90 & 7,58 & 27,12 \\
\hline
\end{tabular}

${ }^{1}$ Calculado por equação proposta por POPINIGIS (1977).

${ }^{2}$ Médias seguidas de letras distintas, comparadas nas colunas, diferem entre si pelo teste de Duncan a 5\% de probabilidade de erro.

avaliado. Segundo OGG Jr. \& SEEFELDT (1999), o rápido crescimento da planta em estatura permite que ela utilize o recurso luz com maior intensidade, podendo sombrear as plantas daninhas já no início do ciclo.

Paralelamente à estatura de planta, o acúmulo de área folhar também apresenta influência sobre a capacidade das plantas em sombrear seus vizinhos. Em casa-de-vegetação, Ligeirinho e XL 6 destacaram-se em ambos os bioensaios pelo acúmulo precoce de área folhar (Tabela 2). Em adição, no Bioensaio 1, também IR 841 e IRGA 418 mostraram posição de destaque para essa variável. Ainda, na tabela 2, observa-se que, no experimento em campo, houve menor diferenciação entre os genótipos quanto a essa variável.

Os genótipos Bluebelle e EEA 406, em ambos os bioensaios, e IRGA 418 e Formosa, no Bioensaio 2, apresentaram as menores áreas folhares na ocasião da avaliação. Já no ensaio em campo, as cultivares Formosa e Bluebelle posicionaram-se abaixo das demais. O genótipo IR 841, embora apresentasse área folhar elevada em ambas as condições, apresentou reduzida estatura de planta (Tabela 2). Isso indica que esta cultivar possui capacidade de acumular elevada superfície de folhas em dossel proporcionalmente baixo. Não houve associação entre estatura de planta e área folhar nos experimentos em casa-de-vegetação.

Tabela 2 - Características de planta de cultivares de arroz, avaliadas em dois bioensaios aos 14 dias após semeadura (DAS) e aos 15 DAS no ensaio em campo, UFRGS, Porto Alegre-RS, 2000/01

\begin{tabular}{|c|c|c|c|c|c|c|c|c|c|}
\hline \multirow{2}{*}{$\begin{array}{l}\text { Cultivares de } \\
\text { arroz }\end{array}$} & \multicolumn{3}{|c|}{ Estatura de planta (cm) } & \multicolumn{3}{|c|}{ Área folhar $\left(\mathrm{cm}^{2} \cdot\right.$ planta $\left.^{-1}\right)$} & \multicolumn{3}{|c|}{ Massa aérea (mg.planta $\left.{ }^{-1}\right)$} \\
\hline & Bionsaio 1 & Bioensaio 2 & Campo & Bioensaio 1 & Bioensaio 2 & Campo & Bioensaio 1 & Bioensaio 2 & Campo \\
\hline IRGA 421 & $15,3 b^{1}$ & $15,4 \mathrm{~d}$ & $11,8 \mathrm{~cd}$ & $2,75 \mathrm{bcd}$ & $1,35 \mathrm{~cd}$ & $3,25 \mathrm{a}$ & $26,8 \mathrm{a}$ & $16,6 \mathrm{~cd}$ & $21,9 \mathrm{a}$ \\
\hline BRS Ligeirinho & $17,7 \mathrm{a}$ & $20,1 \mathrm{a}$ & $14,0 \mathrm{ab}$ & $3,90 \mathrm{a}$ & $1,80 \mathrm{ab}$ & $3,97 \mathrm{a}$ & $26,4 \mathrm{a}$ & $18,5 \mathrm{ab}$ & $22,4 \mathrm{a}$ \\
\hline IRGA 418 & $17,9 \mathrm{a}$ & $17,9 \mathrm{c}$ & $13,5 \mathrm{ab}$ & $3,05 \mathrm{ab}$ & $0,84 \mathrm{e}$ & $3,28 \mathrm{a}$ & $28,6 \mathrm{a}$ & $15,9 \mathrm{~d}$ & $22,8 \mathrm{a}$ \\
\hline XL 6 & $14,1 \mathrm{c}$ & $19,1 \mathrm{~b}$ & $14,6 \mathrm{a}$ & $2,98 \mathrm{abc}$ & $1,91 \mathrm{a}$ & $3,32 \mathrm{a}$ & $24,7 \mathrm{a}$ & $19,5 \mathrm{a}$ & $26,7 \mathrm{a}$ \\
\hline El Paso L 144 & $15,0 \mathrm{bc}$ & $17,8 \mathrm{c}$ & $12,8 \mathrm{bc}$ & $2,61 \mathrm{~cd}$ & $1,60 \mathrm{bc}$ & $3,70 \mathrm{a}$ & $26,1 \mathrm{a}$ & $19,5 \mathrm{a}$ & $24,1 \mathrm{a}$ \\
\hline Bluebelle & $14,0 \mathrm{c}$ & $14,6 \mathrm{e}$ & $10,0 \mathrm{e}$ & $1,83 \mathrm{e}$ & $1,19 \mathrm{~d}$ & $2,07 \mathrm{~b}$ & $18,7 \mathrm{~b}$ & $13,1 \mathrm{e}$ & $13,5 \mathrm{~b}$ \\
\hline IR 841 & $12,1 \mathrm{~d}$ & $15,8 \mathrm{~d}$ & $10,9 \mathrm{de}$ & $3,13 a b$ & $1,64 \mathrm{~b}$ & $3,67 \mathrm{a}$ & $25,5 \mathrm{a}$ & $17,7 \mathrm{bc}$ & $23,1 \mathrm{a}$ \\
\hline IAS Formosa & - & $12,4 \mathrm{f}$ & $7,9 \mathrm{f}$ & - & $0,49 \mathrm{f}$ & $0,98 \mathrm{c}$ & - & $11,5 \mathrm{f}$ & $9,1 \mathrm{c}$ \\
\hline EEA 406 & $16,5 \mathrm{ab}$ & $19,7 \mathrm{ab}$ & - & $2,37 \mathrm{~d}$ & $1,14 \mathrm{~d}$ & - & 29,9 a & $17,8 \mathrm{bc}$ & - \\
\hline Médias & 15,3 & 17,0 & 11,9 & 2,75 & 1,33 & 3,03 & 25,8 & 16,7 & 20,5 \\
\hline CV (\%) & 5,58 & 3,83 & 9,6 & 7,58 & 16,30 & 22,5 & 11,5 & 6,91 & 21,4 \\
\hline
\end{tabular}

${ }^{1}$ Médias seguidas de letras distintas, comparadas nas colunas, diferem entre si pelo teste de Duncan a 5\% de probabilidade de erro.

Ciência Rural, v. 33, n. 4, jul-ago, 2003. 
Contudo, no experimento em campo, constatou-se correlação entre velocidade de emergência e área folhar $(\mathrm{r}=0,58)$ e entre estatura de planta e área folhar $(\mathrm{r}=0,63)$.

Em relação à massa aérea, em ambas as condições experimentais, verificou-se que Formosa e Bluebelle acumularam menor quantidade de massa no período considerado (Tabela 2). Em oposto, XL 6, El Paso e Ligeirinho destacaram-se positivamente pelos acúmulos de massa aérea em ambos os experimentos realizados em casa-de-vegetação, resultado que foi confirmado em campo (Tabela 2). As cultivares IRGA 421, IRGA 418 e IR 841 também se destacaram nessa variável, tanto em campo como no Bioensaio 1. Em campo, constatou-se haver correlações entre massa aérea acumulada com velocidade de emergência $(\mathrm{r}=0,67)$, estatura de planta $(\mathrm{r}=0,61)$ e área folhar $(\mathrm{r}=0,87)$.

O estabelecimento precoce de plântulas de arroz em lavouras é alcançado por rápida emergência e acelerado crescimento inicial de plântulas. Essas características, por sua vez, são dependentes de fatores genéticos das cultivares utilizadas, qualidade fisiológica das sementes e fatores ligados ao ambiente, principalmente temperaturas do ar e do solo e disponibilidade hídrica para germinação das sementes (POPINIGIS, 1977).

\section{CONCLUSÃO}

Cultivares de arroz irrigado apresentam variações nas velocidades de emergência e de crescimento inicial das plântulas.

$\mathrm{O}$ rápido crescimento inicial de plântulas de arroz está associado à sua velocidade de emergência.

O rápido estabelecimento das cultivares de arroz é dependente da velocidade de crescimento em estatura, acúmulo de massa e área folha das plântulas até 15 dias após a semeadura.

As cultivares de arroz irrigado Ligeirinho e XL 6 apresentam rápido estabelecimento de plântulas, enquanto Bluebelle e Formosa mostram lento estabelecimento.

\section{AGRADECIMENTO}

À Fundação de Amparo à Pesquisa no Rio Grande do Sul (FAPERGS) pelo apoio financeiro para desenvolver a pesquisa.

\section{REFERÊNCIAS BIBLIOGRÁFICAS}

CHIKOYE, D.; WEISE, S.F.; SWANTON, C.J. Influence of common ragweed (Ambrosia artemisiifolia) time of emergence and density on white bean (Phaseolus vulgaris). Weed Science, Champaign, v.43, n.3, p.375-380, 1995.

DIARRA, A.; SMITH JR., R.J.; TALBERT, R.E. Growth and morphological characteristics of red rice (Oryza sativa) biotypes. Weed Science, Champaign, v.33, n.3, p.310-314, 1985

DIELEMAN, A. et al. Decision rules for postemergence control of pigweed (Amaranthus spp.) in soybean (Glycine max). Weed Science, Champaign, v.44, n.1, p.126-132, 1996.

EMBRAPA. Centro Nacional de Pesquisa de Solos. Sistema Brasileiro de Classificação de Solos. Brasília : EMBRAPA, 1999. 412p.

FIRBANK, L.G.; WATKINSON, A.R. On the analysis of competition within two-species mixtures of plants. Journal of Applied Ecology, Oxford, n.2, v.22, p.503-517, 1985.

FISCHER, R.A.; MILES, R.E. The role of spatial pattern in the competition between crop plants and weeds. A theoretical analysis. Mathematical Biosciences, New York, v.18, p.335-350, 1973.

GUNEYLI, E.; BURNSIDE, O.C.; NORDQUIST P.T. Influence of seedling characteristics on weed competitive ability of sorghum hybrids and inbred lines. Crop Science, Madison, v.9, n.6, p.713-716, 1969.

KIGEL, J.; GALILI, G. Seed development and germination. New York : Marcel Dekker, 1995. 853p.

KNEZEVIC, S.Z.; HORAK, M.J. Influence of emergence time and density on redroot pigweed (Amaranthus retroflexus). Weed Science, Lawrence, v.46, n.6, p.665-672, 1998.

NI, H. et al. Oryza sativa plant traits conferring competitive ability against weeds. Weed Science, Lawrence, v.48, n.2, p.200-204, 2000.

O'DONOVAN, J.T. et al. Wild oat (Avena fatua) interference in barley (Hordeum vulgare) is influenced by barley variety and seeding rate. Weed Technology, Lawrence, v.14, n.3, p.624-629, 2000 .

OGG JR., A.G.; SEEFELDT, S.S. Characterizing traits that enhance the competitiveness of winter wheat (Triticum aestivum) against jointed goatgrass (Aegilops cylindrica). Weed Science, Lawrence, v.47, n.1, p.74-80, 1999.

POPINIGIS, F. Fisiologia da semente. Brasília : AGIPLAN, 1977. 289p.

RADOSEVICH, S.; HOLT, J.; GHERSA, C. Weed ecology. 2.ed. New York : Wiley, 1997. 588p.

ROMAN, E.S. et al. Modeling germination and seedling elongation of common lambsquarters (Chenopodium album). Weed Science, Lawrence, v.47, n.1, p.149-155, 1999.

SHURTLEFF, J.L.; COBLE, H.D. The interaction of soybean (Glycine $\max$ ) and five weed species in the greenhouse. Weed Science, Champaign, v.33, n.5, p.669-672, 1985. 